\title{
GASTROPROTECTIVE EFFECT OF CURCUMA LONGA LINN. AGAINST ETHANOL INDUCED GASTRIC ULCER IN RATS
}

\author{
Jayan Pariyani Savaringal1, Sanalkumar K. B ${ }^{2}$
}

${ }_{1}^{1}$ Associate Professor, Department of Pharmacology, Government Medical College, Thrissur.

${ }^{2}$ Professor and HOD, Department of Pharmacology, Government Medical College, Thrissur.

ABSTRACT
BACKGROUND
Peptic ulcer is a global health problem, both in terms of morbidity and mortality. There are many treatment strategies for tackling
this disease including proton pump inhibitors, $\mathrm{H}_{2}$ receptor antagonists, ulceroprotectives like prostaglandin analogues and
sucralfate. But they have certain limitations like adverse effects, drug interactions and relapses. Some medicinal plants are found to
be effective in treating and preventing peptic ulcer diseases. Scientific evaluation of these herbal extracts with active chemical
ingredient can be beneficial to find out newer treatment modalities for peptic ulcer diseases with lesser adverse effects and drug
interaction. In the present study, Curcuma longa, a plant belonging to the Zingiberaceae family was chosen for investigating its
antiulcer properties.

\section{MATERIALS AND METHODS}

This is a Comparative Study. The rhizomes of Curcuma longa were collected locally. The extract was prepared by soxlet extraction with 50\% ethanol. Albino rats of Wistar strain (120 - 200 grams) obtained from the animal house of medical college Thiruvananthapuram were used for the study. Sucralfate was purchased from Sigma Labs, Mumbai. Antiulcer effect of the extract was studied in the rat models, where mucosal damage was induced by ethyl alcohol.

\section{RESULTS}

Extract of Curcuma longa exhibited significant protection against alcohol induced gastric damage at dose levels of $1000 \mathrm{mg} / \mathrm{kg}$ body weight comparable to that of standard drug Sucralfate.

\section{CONCLUSION}

The present study with extract of Curcuma longa revealed that it has significant anti-ulcer activity.

\section{KEYWORDS}

Curcuma Longa, Ethyl Alcohol, Anti-Ulcer Effect, Sucralfate.

HOW TO CITE THIS ARTICLE: Savaringal JP, Sanalkumar KB. Gastroprotective effect of curcuma longa lin against ethanol induced gastric ulcer in rats. J. Evolution Med. Dent. Sci. 2018;7(03):332-337, DOI: 10.14260/jemds/2018/74

\section{BACKGROUND}

Peptic ulcer is a global health problem affecting a major part of the world population. Peptic ulcer disease significantly affects quality of life by impairing overall patient's well-being and contributing substantially to work absenteeism. ${ }^{1}$ Factors like increased stress, impaired mucosal resistance, genetic factors, infection with $\mathrm{H}$. pylori and anti-inflammatory drugs like NSAIDs damage gastric mucosa. Anti-inflammatory drugs including NSAIDs are an important proven cause for gastric ulcer, ulcer perforation, gastric and duodenal bleeding and in ulcer death. ${ }^{2}$ Extensive research for NSAIDs with minimum gastric mucosal damage lead to discovery of newer Cox-2 selective NSAIDs. Even though they have minimal gastric mucosal damaging properties, they are devoid of ulcer protective effects and many of them banned due to cardiac adverse effects. Herbal products having antiulcer and ulcer protective properties will be better alternatives with less adverse effects and will have an important place in the pharmacotherapy of peptic ulcer, if they are subjected to

'Financial or Other Competing Interest': None.

Submission 10-12-2017, Peer Review 02-01-2018,

Acceptance 09-01-2018, Published 13-01-2018.

Corresponding Author:

Dr. Jayan Pariyani Savaringal,

Puliyassary Madom, Panniyankara,

Kallai (PO), Calicut-673003, Kerala, India.

E-mail: jayanpsr@gmail.com

DOI: $10.14260 /$ jemds $/ 2018 / 74$ modern research. In the present study, Curcuma longa, a plant belonging to the Zingiberaceae family was chosen for investigating its anti-ulcer actions. Curcuma longa has an important place in the Indian houses, which is considered auspicious in all religious observations and Indian system of medicine. It is used as a germicidal and counterirritant. It is also used in diabetes, indolent ulcers and leprosy. It is also used in flatulence, dyspepsia and weak state of stomach. Various studies shows many beneficial effects of Curcuma longa extract on Gastric mucosa.

\section{Peptic Ulcer ${ }^{3,1}$}

Most simply a peptic ulcer can be defined as disruption of the mucosal integrity of stomach and/ or duodenum leading to a local defect or excavation due to active inflammation. Ulcers are defined as breaks in mucosal surface $>5 \mathrm{~mm}$ in size with depth to the submucosa. Ulceration of the stomach mainly develops in the antral region due to lesions in the gastric mucosa. Since in majority of cases it is aggravated due to pepsin and hydrochloric acid, it is termed as peptic ulcer. Natural course of ulcer disease is characterised by numerous episodes of spontaneous healing, frequent relapses and occasional complications.

\section{Pathogenesis}

Gastric ulcer is a multifactorial disease. Gastroduodenal mucosal injury results from an imbalance between the factors that damage the mucosa and those that protect it. 


\begin{tabular}{|c|c|}
\hline Aggressive Factors & Defensive Factors \\
\hline Gastric acidity & Prostaglandins \\
\hline Pepsin & Bicarbonate \\
\hline Bile acids & Mucus \\
\hline Impairment of motility & Phospholipids \\
\hline Nicotine & Epidermal growth factors \\
\hline NSAIDS & Intact microcirculation \\
\hline Corticosteroids & Epithelial renewal \\
\hline H. pylori & Alkaline tide \\
\hline $\begin{array}{c}\text { Table 1. Aggressive and Defensive Factors affecting the } \\
\text { Integrity of Gastric Mucosa }\end{array}$ \\
\hline
\end{tabular}

\section{Acid and Gastrin}

Patients with gastric ulcer associated with duodenal ulcer have increased postprandial gastrin and increased maximal acid output. This supports the hypothesis that defects in pyloric emptying mechanism with subsequent high gastrin release and high acid secretion predispose to peptic ulcer.

\section{Pepsin and Pepsinogen}

Postprandial pepsin secretion in gastric ulcer patients reported to be lower than normal. Raised serum PG2 and low PG1/PG2 ratios appear to be major risk factors for gastric ulcer occurring at distal third of the stomach.

Gastric emptying: - One accepted hypothesis in the pathogenesis of gastric ulceration is a delay in gastric emptying. It can be due to gastric hypomotility.

\section{Duodenogastric Reflux}

Another hypothesis for the pathogenesis of gastric ulceration is that because of abnormal motility in the antropyloric region, there is reflux of duodenal contents into the stomach, giving rise to chronic inflammation and eventually ulceration.

\section{Mucous}

The epithelial cells and mucous neck cells of the stomach secrete into its surface a layer of mucous, which is an insoluble viscous gel that entraps bicarbonate secreted by the mucosa in a layer.

\section{The Mucous}

Bicarbonate barrier is thus believed to be an important mechanism that enables the gastric as well as duodenal epithelium to remain intact in the face of high concentration of luminal hydrogen ion at $\mathrm{pH} 1.5$ to 2 . Gastric mucosal cells will be less in the gastric mucosa of patients with gastric ulcer. A prevalence of non-secreting surface mucous cells has been observed by scanning electron microscope in patients with gastric ulcer.

\section{Injurious Factors}

The upper gastrointestinal mucosa is susceptible to injury from variety of factors. Important endogenous agents include acid, pepsin, refluxed bile acids, many cytokines, in particular tumour necrosis factor (TNF)- alpha, leukotrienes and reactive oxygen species (ROS) such as $\mathrm{O}_{2}^{-}, \mathrm{H}_{2} \mathrm{O}_{2}$ and $\mathrm{OH} \cdot$ Exogenous agents include ethanol, aspirin and other NSAIDS, corticosteroids, cigarette smoking, stress and H. pylori infection.

Involvement of reactive oxygen species (ROS) in the pathogenesis of gastric ulceration was evident from various studies. ${ }^{4}$ More than $95 \%$ of the $\mathrm{O}_{2}$ taken by the aerobic organisms is fully reduced to water $\left(\mathrm{H}_{2} \mathrm{O}\right)$ during the process of mitochondrial respiration, a small percentage $(<5 \%)$ of the $\mathrm{O}_{2}$ consumed is converted to semi-reduced species, i.e. the superoxide anion radical $\left(\mathrm{O}_{2}{ }^{-}\right)$, hydrogen peroxide $\left(\mathrm{H}_{2} \mathrm{O}_{2}\right)$ and the hydroxyl radical $(\cdot \mathrm{OH})$. These species are collectively referred to as reactive oxygen species (ROS), which can be highly toxic and their interactions often with cellular macromolecules bring about oxidative damage. The most toxic of the ROS is the hydroxyl radical which is often formed when superoxide anion radical and $\mathrm{H}_{2} \mathrm{O}_{2}$ are exposed to the trace transition metals, iron or copper via metal-catalysed Haber-Weiss reaction. ${ }^{5}$

$\mathrm{Fe}^{3+}+\mathrm{O}_{2}^{-}=\mathrm{Fe}^{2+}+\mathrm{O}_{2}$

$\mathrm{Fe}^{2+}+\mathrm{H}_{2} \mathrm{O}_{2}=\mathrm{Fe}^{3+}+\cdot \mathrm{OH}+\mathrm{OH}^{-}$

The net result is therefore,

$\mathrm{O}_{2}^{-}+\mathrm{H}_{2} \mathrm{O}_{2}=\mathrm{O}_{2}+\cdot \mathrm{OH}+\mathrm{OH}^{-}$

Involvement of ROS in pathogenesis of gastric ulceration was evident from the studies on ischaemia-re-oxygenationinduced gastric mucosal injury. ${ }^{4}$ A growing body of experimental and clinical evidence suggests that gastric mucosal damage by ethanol, 6 non steroidal anti-inflammatory drugs, $^{7}$ stress $^{8}$ and Helicobacter pylori ${ }^{9}$ is mediated through reactive oxygen species. ROS also decreases the level of endogenous antioxidants such as $\alpha$-tocopherol, glutathione and ascorbate and make the mucosa more prone to oxidative damage. In a study conducted by Debashis Bandyopadhyay and coworkers, it was found that melatonin a pineal hormone has potent anti-ulcer activity and this activity is mainly due to melatonins potent antioxidant potential which can scavenge the reactive oxygen species. ${ }^{10}$ All these findings favour the involvement of reactive free radicals in gastric mucosal damage and the role of antioxidants in preventing gastric ulceration.

\section{Protective Factors}

A number of mechanisms work together to protect the mucosa from injury. Mucus-bicarbonate barrier, surfaceactive phospholipids, prostaglandin, mucosal blood flow, cell renewal and migration, antioxidants and antioxidant enzymes and some growth factors contribute the mucosal defense against aggressive factors.

\section{A-Gastric Mucosal Barrier1,3}

Gastric mucosa has the ability to resist the back diffusion of hydrogen $\left(\mathrm{H}^{+}\right)$ions and thus to contain a high concentration of hydrochloric acid within the gastric lumen.

The mucosal defense system can be envisioned as a threelevel barrier, composed of pre-epithelial, epithelial and subepithelial elements. The mucous gel functions as a no stirred water layer impeding diffusion of ions and molecules such as pepsin. Bicarbonate secreted by surface epithelial cells of the gastroduodenal mucosa into the mucous gel forms, a $\mathrm{pH}$ gradient ranging from 1 to 2 at the gastric luminal surface and reaching 6 to 7 along the epithelial cell surface. Surface epithelial cells provide the next line of defense through several factors including mucus production and epithelial cell ionic transporters that maintain intracellular $\mathrm{pH}$ and bicarbonate production. 


\section{B-Cytoprotection ${ }^{3}$}

There are certain mediators, which play important role in cytoprotection. Epithelial cells in the surface produce bicarbonate, which diffuses up from the mucosa to accumulate beneath the mucous layer, creating a thin layer of alkalinity between the mucus and epithelial surface. Epithelial cells also secrete mucus, which form a gel that covers the mucosal surface and physically protects the mucosa. Mucosal blood flow is important in maintaining oxygenation and a supply of nutrients. The hydrophobic layer of phospholipids that coats the luminal membrane of surface epithelial cells is believed to help prevent the back diffusion of hydrophilic agents such as hydrochloric acid. The alkaline tide refers to the mild alkalisation of the blood and mucosa that result from secretion of a molecule of bicarbonate $\left(\mathrm{HCO}_{3}\right.$ -) by parietal cell into the adjacent mucosa for every $\mathrm{H}^{+}$ion that is secreted into gastric lumen. The slight alkalinity may contribute to neutralisation of acid that diffuses back into the mucosa and may augment the effects of mucosal blood flow. Prostaglandins play a central role in gastric epithelial defense and repair. Prostaglandins synthesised in the mucosa of stomach stimulate secretion of both mucus and bicarbonate, inhibit parietal cell secretion and are important in maintaining mucosal blood flow and epithelial cell restitution.

\section{MATERIALS AND METHODS \\ Study Design}

Comparative Study.

\section{Plant Material}

Curcuma longa rhizomes were collected locally and identified pharmacognostically. Its botanical identity was confirmed and certified by the Pharmacognosy unit, Ayurvedic Research Institute (A.R.I), Poojappura, Thiruvananthapuram.

\section{Preparation of Extract}

After washing the rhizome, dried in air and cut into small pieces. Soxlet extraction with $50 \%$ alcohol was used for preparing the extract. The percentage yield was 4.5 .

\section{Animals Used}

Albino rats of Wistar strain (120 - 200 grams) obtained from the animal house of medical college, Thiruvananthapuram, were used. They were fed a standard diet and maintained under standard laboratory conditions.

\section{Drugs}

Sucralfate was collected from Sun Pharmaceuticals, Mumbai.

\begin{abstract}
Antiulcer study by Ethyl Alcohol Induced Mucosal Damage in Rats $11,12,13$

Albino rats weighing 150 - 200 of both sexes were used for the study. They were randomised into 5 groups, each group having 6 animals. They were starved for 18 hours having access to drinking water ad libitum. To prevent cannibalism and coprophagy, they were kept in single cages with raised bottoms of wide wire mesh. Aqueous preparation of extract of Curcuma longa and other compounds were given orally 30 minutes prior to $1 \%$ Ethyl alcohol administration in the following manner.
\end{abstract}

- Group I (control): Distilled water (1 mL/100 gram body weight).
- Group II (standard): Sucralfate in a dose of $250 \mathrm{mg} / \mathrm{kg}$ - body weight suspended in distilled water. ${ }^{14}$

- Group III (test group 1): Ethanolic extract of Curcuma longa in a dose of $250 \mathrm{mg} / \mathrm{kg}$ - body weight suspended in distilled water.

- Group IV (test group 2): Ethanolic extract of Curcuma longa in a dose $500 \mathrm{mg} / \mathrm{kg}$ - body weight suspended in distilled water.

- $\quad$ Group V (test group 3): Ethanolic extract of Curcuma longa in a dose of $1000 \mathrm{mg} / \mathrm{kg}$ - body weight suspended in distilled water.

One $\mathrm{mL}$ of absolute alcohol was administered orally to all animals, 30 minutes after administering the test compounds. One hour after administering ethyl alcohol, the animals were sacrificed by giving heavy dose of ether. Stomach was removed and opened along the greater curvature. Mucosa was examined macroscopically for gastric mucosal damage located in fundic area. For each rat, the total major axis length of ethanol induced lesions was measured. ${ }^{15}$

\section{Statistical Analysis}

One-Way ANOVA (Analysis of Variance) was done to compare the means in the experimental groups. Mean and standard deviation was found out. Significance of test results were done by Duncan's Multiple Range (DMR) test (Post-Hoc analysis using DMR test).

\section{RESULTS}

Antiulcer Study by Ethyl Alcohol Induced Mucosal Damage in Rats

Ethanol produced severe band-like mucosal lesions in the fundic glandular portion of the stomach. Extract of Curcuma longa exhibited significant protection against alcohol induced gastric damage at dose levels of $1000 \mathrm{mg} / \mathrm{kg}$ body weight comparable to that of standard drug Sucralfate. There was significant cytoprotective action, but in a lesser extent at 500 $\mathrm{mg} / \mathrm{kg}$ doses of test drug. The extract in the dose of 250 $\mathrm{mg} / \mathrm{kg}$ dose was not effective comparable to that of control. Major axis length of ulcers was 47.98 $\pm 1.90,37.90 \pm 3.02$ and $11.27 \pm 1.34$ in dose levels of $250 \mathrm{mg} / \mathrm{kg}, 500 \mathrm{mg} / \mathrm{kg}$ and $1000 \mathrm{mg} / \mathrm{kg}$ body weight respectively. Major axis length was $9.50 \pm 0.66$ in the sucralfate treated group, whereas $46.32 \pm$ 3.08 in the control group. The alcohol induced gastric lesion is a model for screening cytoprotective action of test drug. The results show significant cytoprotective action of test drug comparable to that of Sucralfate in the dose of $1000 \mathrm{mg} / \mathrm{kg}$ body weight doses. The effect was comparable with that of standard drug Sucralfate.

\begin{tabular}{|c|c|c|c|}
\hline $\begin{array}{c}\text { Group } \\
\text { (No= 6) }\end{array}$ & Drug & $\begin{array}{c}\text { Dose/kg } \\
\text { Body Weight }\end{array}$ & $\begin{array}{c}\text { Major Axis Length } \\
\text { of Ulcers } \\
\text { Mean } \pm \text { SE }\end{array}$ \\
\hline I & Vehicle & & $46.317 \pm 3.081$ \\
\hline II & Sucralfate & 250 & $9.555 \pm 0.663$ \\
\hline III & $\begin{array}{c}\text { Extract of } \\
\text { Curcuma longa }\end{array}$ & 250 & $47.983 \pm 1.895$ \\
\hline IV & $\begin{array}{c}\text { Extract of } \\
\text { Curcuma longa }\end{array}$ & 500 & $37.900 \pm 3.019$ \\
\hline V & $\begin{array}{c}\text { Extract of } \\
\text { Curcuma longa }\end{array}$ & 1000 & $11.267 \pm 1.340$ \\
\hline Table 2. Effect of Ethanolic Extract of Curcuma longa on \\
Ethyl Alcohol Induced Gastric Lesions in Rats \\
\hline \multicolumn{4}{|c}{} \\
\hline
\end{tabular}




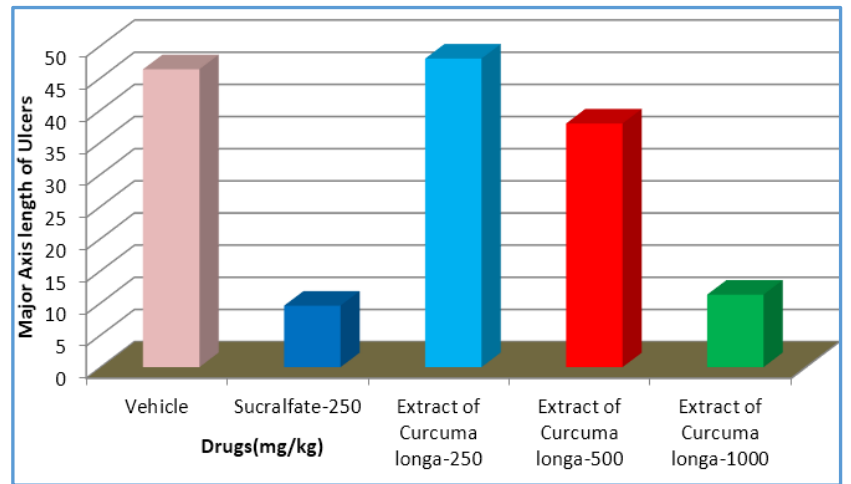

Figure 1. Graph showing the Effect of Ethanolic Extract of Curcuma longa and Sucralfate on Anti-Ulcer Study by Alcohol Induced Gastric Lesions in Rat

\begin{tabular}{|c|c|c|c|}
\hline & \begin{tabular}{|c|} 
Total Ulcer \\
Length - Mean
\end{tabular} & $\begin{array}{l}\text { Standard } \\
\text { Deviation }\end{array}$ & F-value \\
\hline Control & 46.317 & 3.081 & \multirow{5}{*}{$436.391^{* * *}$} \\
\hline Standard & 9.555 & 0.663 & \\
\hline Drug 250 & 47.983 & 1.895 & \\
\hline Drug 500 & 37.900 & 3.019 & \\
\hline Drug 1000 & 11.267 & 1.340 & \\
\hline $\begin{array}{r}\text { Table } 3 . \\
\text { of } \\
\end{array}$ & $\begin{array}{l}\text { sis of } \mathrm{Va} \\
\text { Alcohol }\end{array}$ & $\begin{array}{l}\text { for Tot } \\
\text { Gastri }\end{array}$ & $\begin{array}{l}\text { er Length } \\
\text { ions }\end{array}$ \\
\hline
\end{tabular}

$\mathrm{n}=6$

-*p $<0.05 ;{ }^{* *} \mathrm{p}<0.01 ;{ }^{* * *} \mathrm{p}<0.001$

\begin{tabular}{|c|c|c|c|}
\hline \multirow{2}{*}{ Groups } & \multicolumn{3}{|c|}{ Subset of alpha= .05 } \\
\cline { 2 - 4 } & $\mathbf{1}$ & $\mathbf{2}$ & $\mathbf{3}$ \\
\hline Standard & 9.5555 & & \\
\hline Drug 1000 & 11.2667 & & \\
\hline Drug 500 & & 37.9000 & \\
\hline Drug 250 & & & 47.983 \\
\hline Control & & & 46.317 \\
\hline
\end{tabular}

Table 4. Post-Hoc Tests (Analysis)- Homogeneous SubsetsDuncan's Multiple Range (DMR) Test for Ethyl Alcohol Induced Gastric Lesions

Means for groups in homogeneous subset are displayed. Uses Harmonic Sample size $=6.000$.

\section{DISCUSSION}

Curcuma longa has been used in traditional medicine for treating various diseases. The present study supports the traditional use of this plant against gastric problems. Here, extract of Curcuma longa showed gastric mucosal protection comparable to Sucralfate. Pharmacological evaluation of compound UP5145 showed cytoprotective action leading to antiulcer property. ${ }^{15}$ Free radical injury is a causative factor for ethyl alcohol induced peptic ulcers. ${ }^{16}$ In the present study, extract of Curcuma longa showed a significant protection against the experimental ulcers induced by ethyl alcohol. Extract of Curcuma longa on various models suggests its diverse role in ulcer protection, which may include its reported effect on wound healing 17 and as an anti-oxidant. The effect of gastric mucosal cells of patients with gastric ulcer have been considered immature and incapable of producing adequate mucin, which histologically appears to be decreased in the mucosa of such patients.18 Use of natural drugs in gastric ulcers is well documented.19,20,21 Most of these drugs augment the mucosal defensive factors, which are thought to be important for protection of gastric mucosa. ${ }^{22}$ Peptic ulcers are reported to be due to an imbalance between offensive acid-pepsin secretion and defensive mucosal factors like mucin secretion and cell shedding. ${ }^{23}$ Extract of Curcuma longa found to have many protective effects on stomach. P-tolymethylcarbinol, a turmeric component, was found capable of increasing bicarbonate and pancreatic enzyme secretion. ${ }^{24}$ It is found to increase gastric wall mucus. ${ }^{25}$ In another study, oral administration of Curcumin in rats caused reversal of lipid peroxidation in brain lipids and produced enhancement of glutathione, a non-enzymatic antioxidant. ${ }^{26}$ In case of peptic ulcer, inflammatory mediators play an important role along with involvement of free radical injury and lipid peroxidation. Study conducted by Illuri and coworkers shows potent acute anti-inflammatory activity of Curcuma longa in carrageenan induced paw oedema and xylene induced ear oedema and chronic anti-inflammatory activity in cotton pellet induced granuloma model. ${ }^{27}$ Potent antioxidant and free radical scavenging properties of Curcuma longa extract in FRAP (Ferric reducing antioxidant power) assay shown by Ranjith Thakur and coworkers may contribute to its cytoprotective action. ${ }^{28}$ Potent anti-inflammatory activity of Curcuma longa was shown by Anandakumar and coworkers. ${ }^{29}$ Antiinflammatory and antioxidant activity of curcuma longa was also shown in a study done by Esatbeyoglu T et al.30

Free radical scavenging, antioxidant and increasing glutathione levels may contribute to the anti-ulcer effect of curcumin. ${ }^{31}$ Mahady GB and coworkers showed anti H. pylori effect for the extract of Curcuma longa. ${ }^{32} \mathrm{H}$. pylori is a gramnegative spiral bacterium that is associated with chronic gastritis, peptic ulcer and a risk factor for gastric malignancies such as adenocarcinoma and mucosa associated lymphoid tissue (MALT) lymphoma. ${ }^{33}$ In a study conducted by Soney EK and coworkers, diarylheptanoids separated from ethanolic extract of curcuma longa found to have free radical scavenging activity in vitro. ${ }^{34}$ Thus, the potent antiinflammatory anti H. pylori and antioxidant effect of Curcuma longa extract and curcumin may help in the acute and chronic peptic ulcer management complicated by concomitant $\mathrm{H}$. pylori infection. The anti-cancer properties may also be helpful in the long-term treatment of peptic ulcer complicated by $\mathrm{H}$. pylori infection since infection with $\mathrm{H}$. pylori is considered as a risk factor for gastric malignancies. ${ }^{33}$

Oxygen free radicals are implicated in the pathogenesis of ethanol induced gastric mucosal injury ${ }^{6}$ apart from other mechanisms, such as mucosal leukotriene release ${ }^{35}$ and submucosal venular constriction. ${ }^{36}$ Ethanol induced gastric injury is associated with significant production of free radicals, leading to increased lipid peroxidation which causes damage to cell and cell membranes. ${ }^{37}$ Accumulation of activated neutrophils in the gastric mucosa may be a source for free radicals. ${ }^{38}$ In this study, extract of Curcuma longa exhibited significant protection of rats from ethanol induced mucosal injyry. It may be due to its antioxidant effect. Extract of Curcuma longa exerts its beneficial effect by reducing cellular circulating reactive oxygen species (ROS) characterised by increased lipid peroxidation and decreased antioxidant status. ${ }^{39}$ It has also been reported that leukotriene antagonist and 5-lipoxygenase inhibitors are capable of inhibiting alcohol and NSAID's-induced gastric ulceration in rats, 40 so the protection afforded by the extract of Curcuma longa against alcohol induced gastric ulceration 
could also be due to inhibition of 5-lipoxygenase pathway or leukotriene antagonistic activity. Further studies are necessary to confirm these findings.

\section{CONCLUSION}

The present study with extract of Curcuma longa revealed that it has significant anti-ulcer properties. Further studies have to be conducted to explain precisely the mechanism of action of this drug.

\section{REFERENCES}

[1] Valle JD. Peptic ulcer disease and related disorders. In: Kasper DL, Fauci AS, Hauser SL, et al. eds. Harrison's Principles of internal medicine. Vol 2. 19th edn. New York: McGraw-Hill 2015:1911-12.

[2] William S, Schaffner F, Berk E, et al. Gastroenterology. Vol 1. $5^{\text {th }}$ edn. WB Saunders Company 1995;714-32.

[3] William S, Schaffner F, Berk E, et al. Gastroenterology. Vol 1. $5^{\text {th }}$ edn. WB Saunders Company 1995;714-32.

[4] Perry MA, Wadhawa S, Parks DA, et al. Role of oxygen radicals in ischemia-induced lesions in the cat stomach. Gastroenterology 1986;90(2):362-7.

[5] Bandyopadhyay D, Biswas K, Bhattacharyya M, et al. Involvement of reactive oxygen species in gastric ulceration: protection by melatonin. Indian J Exp Biol 2002;40(6):693-705.

[6] Hiraishi $H$, Shimuda $T$, Ivey $K J$, et al. Role of antioxidant defenses against ethanol-induced damage in cultured rat gastric epithelial cells. J Pharmacol Exp Ther 1999;289(1):103-9.

[7] Rainsford KD. Mechanisms of gastro-intestinal ulceration by non-steroidal antiinlammatory/analgesic drugs. Adv Inflam Res 1984;6:51-64.

[8] Miller TA. Mechanism of stress - related mucosal damage. Am J Med 1987; 83(6A):8-14.

[9] Davis GR, Simmonds NJ, Stevens TRJ, et al. Helicobacter Pylori stimulates antral mucosal reactive oxygen metabolite production in vivo. Gut 1994;35(2):179-85.

[10] Bandyopadhyay D, Biswas K, Bhattacharyya M, et al. Involvement of reactive oxygen species in gastric ulceration: protection by melatonin. Indian J Exp Biol 2002; 40(6):693-705.

[11] Robert A, Nezamis JE, Lancaster C, et al. Cytoprotection by prostaglandins in rats. Prevention of gastric necrosis produced by alcohol, $\mathrm{HCL}, \mathrm{NaOH}$, hypertonic saline and thermal injury. Gastroenterology 1979;77(3):433-43.

[12] Parmar NS, Desai JK. A review of the current methodology for the evaluation of gastric and duodenal anti-ulcer agents. Indian J Pharmacol 1993;25(3):120-35.

[13] Abebaw M, Mishra B, Gelayee DA. Evaluation of antiulcer activity of the leaf extract of Osyris quadripartite Decne (Santalaceae) in rats. Journal of Experimental Pharmacology 2017;9:1-11.

[14] Sairam K, Rao CV, Goel RK. Effect of Canvolvulus pluricaulis chois on gastric ulceration and secretion in rats. Indian J Exp Biology 2001;39(4):350-4.

[15] Dedieu-Chaufour C, Herts F, Caussade F, et al. Pharmacological profile of UP 5145-52, an original anti-ulcer and anti-secretory agent. The Journal of Pharmacol and Experimental Therapeutics 1991;259(1):190-7.

[16] Mizui T, Doteuchi M. Lipid peroxidation: a possible role in gastric damage induced by ethanol in rats. Life Sci 1988;42:1757-60.

[17] Gujral ML, Chowdhury NK, Saxena PN. Wound healing property of curcuma powder. Indian Med Assoc 1953;22:273.

[18] Domschke W, Domschke S, Hagel J, et al. Gastric epithelial cell turn over mucous production and healing of gastric ulcers with carbenoxolone. Gut 1977;18(10):817-20.

[19] Goel RK, Sairam K. Anti-ulcer drugs from indigenous sources with emphasis on Musa sapientum, Tamrabhasma, Asparagus racemosus, and Zingiber officinale. Indian J Pharmacol 2002;34(2):100-10.

[20] Hiruma-Lima CA, Gracioso JD, Toma W, et al. Evaluation of the gastroprotective activity of cordatin, a diterpene isolated from Aparisthmium cordatum (Euphorbiaceae). Biol Pharm Bull 2000;23(12):14659.

[21] Antonio MA, Brito SAR. Oral anti-inflammatory and anti-ulcerogenic activities of a hydroalcoholic extract and partitioned fractions of Turnera ulmifolia (Turneraceae). J Ethnopharmacol 1998;61(3):215-28.

[22] Goel RK, Gupta Saroj, Shankar R, et al. Anti-ulcerogenic effect of Banana powder (Musa sapientum var. paradisiaca) and its effects on mucosal resistance. J Ethnopharmacol 1986;18(1):33-44.

[23] Goel RK, Bhattacharya SK. Gastroduodenal mucosal defence and mucosal protective agents. Indian J Exp Biol 1991;29(8):701-14.

[24] Ammon HPT, Wahl MA. Pharmacology of Curcuma longa. Planta Medica 1991;57(1):1-7.

[25] Rafathullah S, Tariq M, Al-Yahya MA, et al. Evaluation of turmeric (Curcuma longa) for gastric and duodenal anti-ulcer activity in rats. J Ethanopharmacol 1990;29(1):25-34.

[26] Rajakrishnan V, Viswanathan P, Rajasekharan KN, et al. Neuroprotective role of curcumin from curcuma longa on ethanol-induced brain damage. Phytother Res 1999;13(7):571-4.

[27] Ramanaiah I, Bethapudi B, AnandaKumar S, et al. Antiinflammatory activity of polysaccharide fraction of Curcuma longa extract. Anti-inflammatory and AntiAllergy Agents in Medicinal Chemistry 2015;14(1):5362.

[28] Thakur R, Yadav K, Khadka KB. Study of antioxidant, anti-bacterial and anti-inflammatory activity of cinnamon, ginger and turmeric. American Journal of Life Sciences 2013;1(6):273-7.

[29] Senthilkumar A, Allan JJ, Bharathi B, et al. Antiinflammatory effect of Turmeric (Curcuma longa L.) Extract on acute and chronic inflammation models. Journal of Korean Society of Food Science and Nutrition 2014;43(4):612-7.

[30] Esatbeyoglu T, Ulbrich K, Rehberg C, et al. Thermal stability, antioxidant and anti-inflammatory activity of curcumin and its degradation product 4 vinyl guaiacol. Food and Function 2015;6(3):887-93. 
[31] Pizorrno JE, Murray MT. Textbook of natural medicine. $2^{\text {nd }}$ edn. London: Churchill Livingstone 1999:689-93.

[32] Mahady GB, Pendland SL, Yun G, et al. Turmeric (Curcuma longa) and curcumin inhibit the growth of Helicobacter pylori, a group 1 carcinogen. Anticancer Res 2002;22(6C):4179-81.

[33] Ananthanarayanan, Jayarampaniker RK. Textbook of Microbiology. 10 th edn. Orient Longman Pvt Ltd., 2017:407-08.

[34] Song EK, Cho H, Kim JS, et al. Diaryl heptanoids with free radical scavenging and hepatoprotective activity in vitro from Curcuma longa. Planta Med 2001;67(9):876-7.

[35] Peskar BM, Lange K, Hoppe U, et al. Ethanol stimulates formation of Leukotriene C4 in rat gastric mucosa. Prostaglandins 1986;31(2):283-93.
[36] Oates PJ, Hakkineu JP. Studies on the mechanism of ethanol-induced gastric damage in rats. Gastroenterol 1988;94(1):10-21.

[37] Fridovich I. The biology of free radicals. Science 1978;201(4359):875-80.

[38] Tepperman BL, Soper BD. Effect of sialoadenoectomy on ethanol-induced gastric mucosal damage in rat:role of neutrophils. Canad J Physiol Pharmacol 1990;68(2):207-10.

[39] Balasubramanyam M, Koteswari AA, Kumar RS, et al. Curcumin-induced inhibition of cellular reactive oxygen species generation: novel therapeutic implications. J Biosci 2003;28(6):715-21.

[40] Parnaham MJ, Brune K. Agents action. 1987;21:232. 